D.O.I: $10.3895 / \mathrm{S} 1808-04482013000100012$

\title{
EFETIVIDADE DAS AUDITORIAS DA QUALIDADE REALIZADAS POR MONTADORAS EM INDÚSTRIAS DE AUTOPEÇAS
}

\section{EFFECTIVENESS OF QUALITY AUDITS PERFORMED BY AUTOMAKERS ON SUPPLIERS}

\author{
Alexandre Casimiro da Silva ; Stella Regina Reis da Costa ${ }^{2}$ \\ ${ }^{1}$ Universidade Federal Rural do Rio de Janeiro - UFRRJ - Seropédica - Brasil \\ alexandrebama@hotmail.com \\ ${ }^{2}$ Universidade Federal Rural do Rio de Janeiro - UFRRJ - Seropédica - Brasil \\ stella@ufrrj.br
}

\begin{abstract}
Resumo
A presente pesquisa objetiva identificar como aumentar a efetividade das auditorias da qualidade realizadas por montadoras em seus fornecedores de autopeças. A metodologia de pesquisa adotada foi o questionário, com uma amostra formada por profissionais dos fornecedores de autopeças instalados no Brasil, que são constantemente auditados pelos seus clientes, as montadoras. Foi identificado que, a despeito da reputação, a auditoria é considerada efetiva na maioria das vezes $e$ que problemas de competência e qualificação dos auditores, juntamente com a análise tendenciosa de evidências de auditoria são os pontos que mais têm prejudicado a efetividade da mesma. Sobre tais pontos são propostas ações de melhoria.
\end{abstract}

Palavras-chave: qualidade; auditoria; montadoras.

\section{Introdução}

Um exame independente e documentado, um "mal necessário", um momento de stress. A auditoria pode ser definida de diferentes formas. São realizadas auditorias de diferentes tipos tais como finanças, software, ambiental, segurança e qualidade. A auditoria mobiliza tempo e outros recursos e é razoável dizer que se espera dela um resultado prático além de apenas um relatório de auditoria.

As fabricantes de veículos são comumente chamadas de montadoras e compram peças dos fornecedores de autopeças. A qualidade das peças influencia diretamente a qualidade do veículo e por isso as montadoras possuem departamentos, normas e procedimentos específicos para assegurar a qualidade de seus fornecedores. A auditoria da qualidade é uma das ferramentas usadas no processo de asseguramento e melhoria da qualidade. A auditoria precisa ser efetiva para promover a melhoria e o asseguramento da qualidade. 
O artigo está focado no problema da efetividade da auditoria, e tem como objetivo identificar como aumentar a efetividade das auditorias da qualidade, realizadas por montadoras, na melhoria contínua da qualidade em fornecedores de autopeças. O trabalho está dividido em introdução e mais quatro partes: referencial teórico, método, resultados e discussão e conclusão.

O referencial teórico contempla tópicos sobre certificação, auditoria, processos e efetividade. O método descreve a aplicação do questionário para realização da pesquisa. Os resultados e discussão apresentam as análises da pesquisa de campo que embasam as conclusões do trabalho.

O estudo sobre a aplicação de técnicas ligadas à qualidade na indústria automobilística é justificável porque esta "tem estado, desde o princípio, na liderança em termos de gerenciamento da qualidade" (IWAARDEN, WIELE e WILLIAMS, 2006, p.103).

É relevante citar o peso da indústria automobilística na economia brasileira de um modo geral, onde é responsável por $21 \%$ do PIB industrial nacional, conforme dados da ANFAVEA (2012).

A pesquisa visando a melhora na efetividade de uma ferramenta, aplicada no trabalho de interface entre montadoras e fornecedores, de uma indústria relevante para o país, constitui o cerne da justificativa deste trabalho.

\section{Referencial Teórico}

\subsection{Certificações da qualidade}

Os fornecedores de autopeças precisam obter certificações conforme normas internacionais da qualidade para atender às exigências das montadoras (HERNANDEZ, 2010).

O termo certificação possui mais de uma definição. No contexto do trabalho apresentado, será usada a norma ISO 17021 (2011), que define certificação como o procedimento pelo qual uma terceira parte independente dá garantia escrita que um sistema, produto, processo ou serviço está em conformidade com determinados requisitos ou normas. O termo "terceira parte" segundo Arter (2003) se aplica às auditorias feitas por organismos certificadores independentes, responsáveis pela realização de auditorias de certificação.

Em relação à sistemas de gerenciamento da qualidade, as normas ISO série 9000 ocupam posição de destaque em todos os ramos da indústria.

O início do progresso da certificação da qualidade no Brasil, conforme as normas ISO série 9000, é descrito por Santos (2007):

Pode-se dizer que a década de 1990 foi decisiva para as normas ISO no Brasil. Até meados de 1992, não eram sequer muito conhecidas no meio organizacional brasileiro, muito menos aplicadas. Já em 1994 em torno de 30\% das indústrias já as tinham implantado ou tinham essa intenção. A série de normas ISO 9000 surgiu em 1987, baseadas em normas 
Hernandez (2010) afirma que a aplicação e aceitação das normas ISO série 9000 tem crescido de forma singular desde seu surgimento em 1987 e que as mesmas tornaram-se referência básica para sistemas de gerenciamento da qualidade em todo o mundo.

O crescimento da certificação conforme normas da ISO série 9000, aliado ao aumento da diversidade das normas de auditorias das montadoras levou à existência de diferentes normas e requisitos aos quais os fornecedores de autopeças deveriam se adequar.

O IATF (International Automotive Task Force, ou Força-Tarefa Automotiva Internacional) foi criado tendo como membros montadoras e associações de diferentes países, com o objetivo de uniformizar os requisitos de sistema da qualidade na cadeia de suprimentos da indústria automotiva em nível global. A publicação mais conhecida do IATF é a especificação técnica ISO/TS 16949, que foi desenvolvida por membros do IATF e submetida à ISO para aprovação e publicação.

Hoje a certificação conforme ISO/TS 16949 é exigida a praticamente todos os fornecedores que entregam peças diretamente às montadoras no Brasil.

Outras certificações comuns na indústria automobilística são:

- ISO 14001:2004 (ou NBR ISO 14001:2004): Norma que especifica os requisitos relativos a um sistema da gestão ambiental.

- BS OHSAS 18001:2007: Norma que especifica os requisitos para sistema de gerenciamento de saúde e segurança ocupacional.

O processo de certificação depende principalmente de um resultado positivo em uma auditoria de terceira parte.

\subsection{Definições de Auditoria}

A ISO, Organização Internacional para Normalização, sediada em Genebra, define Auditoria como:

Um processo sistemático, independente e documentado para obter-se evidência de auditoria e avaliá-la objetivamente de forma a determinar o grau de cumprimento do critério de auditoria (Guidelines for auditing management systems, ISO Q19011:2011, 2011, p.1).

A norma ISO 19011 (2011) descreve o guia para auditoria de sistemas de gerenciamento e define termos aplicáveis ao contexto deste trabalho:

- Evidência de auditoria - registros ou outras informações verificáveis e relevantes em relação ao critério de auditoria;

- Critério de auditoria - conjunto de políticas, procedimentos ou requisitos contra os quais as evidências de auditoria são avaliadas. 
Munro (2003) define auditoria como um processo de se comparar a realidade com os requisitos.

As auditorias podem ser classificadas por tipos sob dois focos diferentes: quem faz (primeira, segunda e terceira partes) e o que é auditado (produto, sistema e processo) conforme Silva (2009), Arter (2003), Munro (2003) e Russell (2007).

Uma representação gráfica dos tipos de auditoria, divididos em dois eixos básicos: quem audita e o que é auditado, é apresentada na Figura 1.

Figura 1 - Os tipos de auditoria em dois eixos

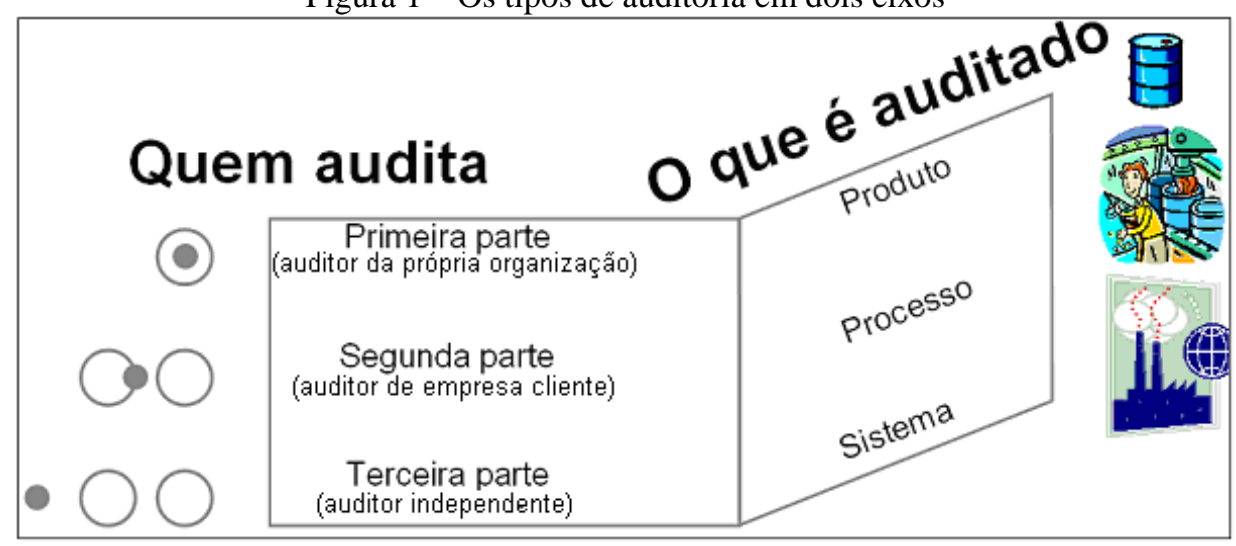

Fonte: Autoria própria (2011)

Os eixos são independentes, podendo haver auditorias de produto realizadas por auditores de primeira, segunda ou terceira parte. $\mathrm{O}$ mesmo vale para as auditorias de processo e sistema.

\subsection{Tipos de Auditoria - sob o foco de "quem audita"}

Uma divisão dos tipos de auditoria, sob o foco de quem audita, é descrita por Arter (2003) e Russell (2007):

- Auditorias de primeira parte (ou auditorias internas): Aquelas realizadas pela própria empresa ou a seu pedido.

- Auditorias de segunda parte: Aquelas realizadas por empresa cliente nas instalações e processos de seus fornecedores. Este tipo de auditoria inclui as auditorias de montadoras, objeto desta pesquisa.

- Auditorias de terceira parte: Auditorias realizadas por organismos de certificação ou órgãos governamentais que visam certificar (ou não) uma empresa, processo ou produto em relação à uma norma específica.

Auditorias de primeira parte podem ser usadas na preparação para auditorias de segunda ou terceira partes, conforme Russell (2007). 


\subsection{Tipos de Auditoria - sob o foco do "que é auditado"}

Silva (2009) lista 3 tipos de auditorias: de sistema, de produto e de processo, apresentando um resumo da engrenagem entre eles na Figura 2:

Figura 2 - Engrenagem entre auditorias de sistema, processos e produto

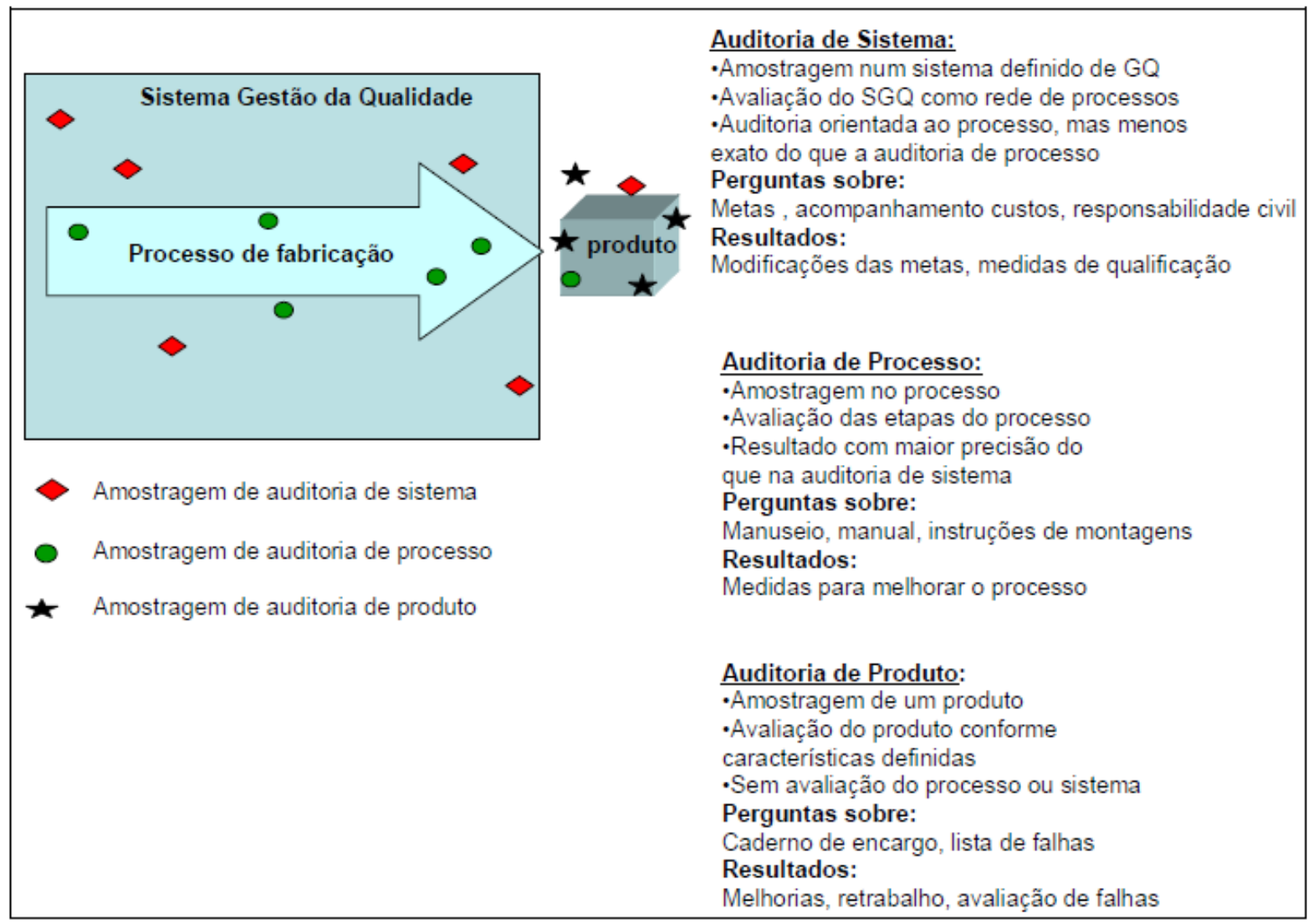

Fonte: Silva (2009, p.57)

Arter (2003) e Russel (2007) detalham os tipos de auditoria:

- Auditoria de Produto: atividade similar à uma inspeção, onde produtos são examinados em relação aos seus requisitos, tais como normas e desenhos. Auditorias de produto podem implicar em destruição de amostras para a realização de testes.

- Auditoria de Processo: exame de um processo objetivando verificar se os recursos, insumos, ações e produtos estão em acordo aos requisitos definidos. Qualquer processo pode ser auditado, por exemplo: pintar um carro, fazer um pedido de compra, selecionar um funcionário.

- Auditoria de Sistema: exame de todo um sistema que pode ser composto por diversos processos e produtos. Uma auditoria de sistema percorre a organização em um nível macro, ao passo que auditorias de processo e produto estarão normalmente ligadas a poucas atividades e produtos. 
Russel (2007) propõe um modelo que ilustra o escopo de cada um dos 3 tipos de auditoria (sistema, processo e produto), mostrado na Figura 3.

Figura 3 - Diferentes tipos de auditoria

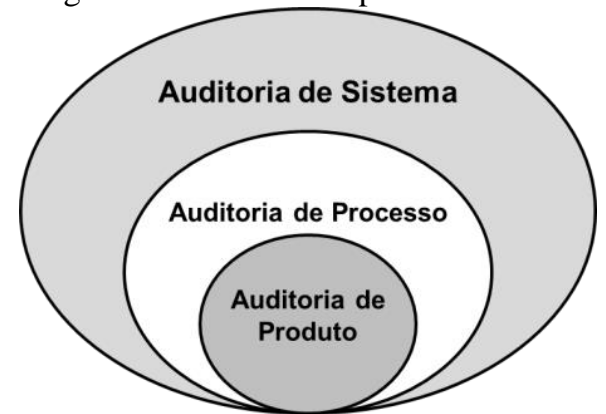

Fonte: Russell (2007, p.8). Tradução do autor

Munro (2003) afirma que, com a revisão das normas ISO Série 9000 (em 2000), houve um aumento no interesse sobre a Abordagem de Processos para a gestão de organizações, pois o princípio número 4 para a Gestão da Qualidade diz:

Um resultado desejado é atingido de forma mais eficiente quando atividades e recursos a elas relacionados são administrados como um processo (Quality management systemsFundamentals and vocabulary, ANSI/ISO/ASQ Q9000-2000.2000, ix).

O item 0.2 da especificação técnica ISO/TS16949 (2009), baseada na norma ISO 9001 (2008), promove a adoção da abordagem de processos. O AIAG (Automotive Industry Action Group) apresenta a seguinte definição para o termo:

A aplicação de um sistema que identifique os processos de uma organização, as interações entre eles e o seu gerenciamento pode ser definida como "abordagem de processo".

Uma vantagem da abordagem de processo é o controle que ela fornece sobre as ligações entre os processos individuais com o sistema de gerenciamento da qualidade, assim como sobre as suas sequências e interações (ISO/TS 16949:2002 Implementation Guide, AIAG, 2003, p.11).

Munro (2003) complementa que esta atenção maior em relação aos processos naturalmente implica em uma atenção também maior nas auditorias de processo.

Um resumo dos principais termos relativos ao tema auditoria é apresentado no Quadro 1, elaborado por Karapetrovic e Willborn (2000). 
Quadro 1 - Diagrama conceitual sobre auditoria

\section{SISTEMA}

Conjunto de diferentes processos que funcionam harmoniosamente, utilizando recursos humanos, materiais, informações e infraestruturas para alcançar determinados objetivos.

\section{SISTEMA DE AUDITORIA}

Conjunto de programas de auditorias independentes planejadas e realizadas para cumprir as politicas $e$ atingir aos objetivos das auditorias.

\section{PROGRAMA DE AUDITORIA}

Conjunto de auditorias interdependentes, planejadas e realizadas para cumprir os objetivos de auditoria da organização.

\section{POLÍTICA DE AUDITORIA}

Declaração de intenções e princípios relacionados ao desempenho geral do sistema de auditoria que define uma forma de conduta e os objetivos da auditoria (baseado na norma ISO 14011,1996)

\section{PROCESSO DE AUDITORIA}

Conjunto de atividades inter-relacionadas de auditoria que transformam escopo, objetivos $e$ critérios em achados de auditoria e conclusões.

\section{RECURSOS DE AUDITORIA}

Recursos tais como auditores, métodos, infraestrutura e informação que são usados para atingir objetivos de auditoria e cumprir com as políticas de auditoria.

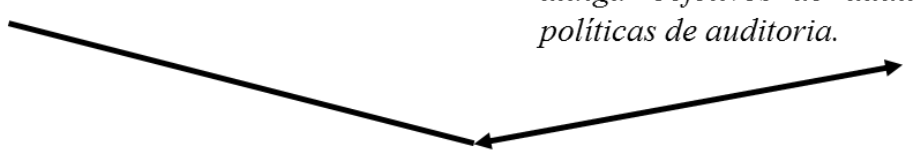

\section{AUDITORIA}

Um processo sistemático, independente e documentado para obter-se evidência de auditoria e avaliá-la objetivamente de forma a determinar o grau de cumprimento do critério de auditoria e reportar os achados de auditoria, tendo em conta o risco de auditoria e sua relevância.

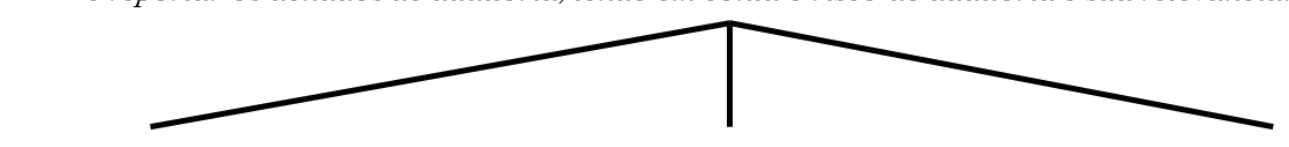

\section{AUDITORIA DE} PROCESSO

Auditoria de um processo especifico com requisitos documentados de processo.

\section{AUDITORIA DA QUALIDADE}

Auditoria de um sistema de gerenciamento da qualidade.

\section{AUDITORIA DE SISTEMA} Auditoria de um determinado sistema de gerenciamento.
AUDITORIA DE PRODUTO Auditoria de um produto especifico conforme seus requisitos.

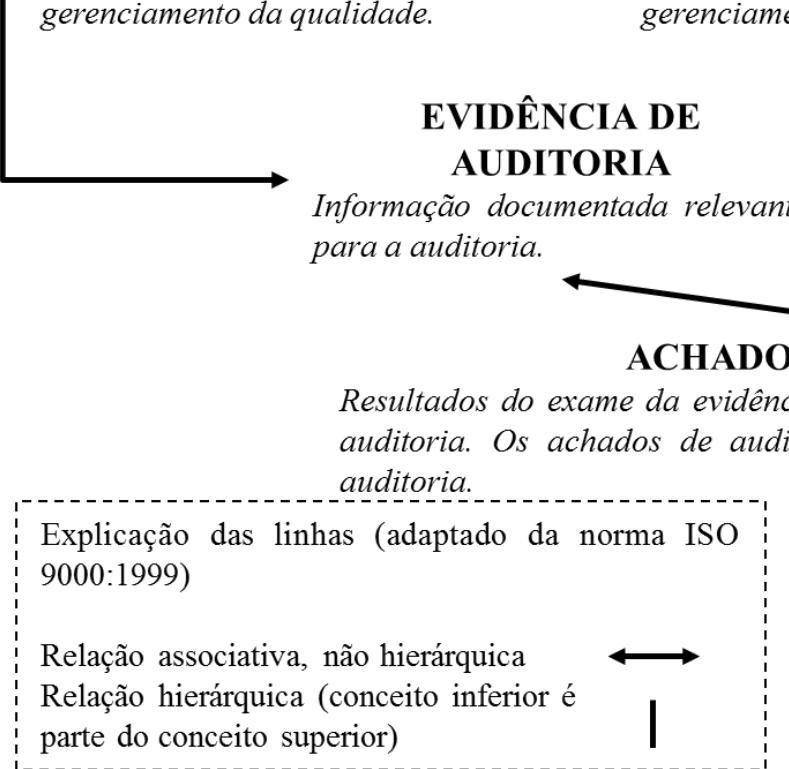

\section{AUDITORIA \\ AMBIENTAL}

Auditoria de um sistema de gerenciamento ambiental.

\section{AUDITORIA DE SEGURANÇA}

Auditoria de um sistema de gerenciamento da segurança do trabalho.
EVIDÊNCIA DE

AUDITORIA

Informação documentada relevante para a auditoria.

\section{CRITÉRIO DE AUDITORIA}

Políticas, procedimentos, normas ou requisitos usados como referência na auditoria.

\section{ACHADO DE AUDITORIA}

Resultados do exame da evidência de auditoria em relação ao critério de auditoria. Os achados de auditoria são documentados no relatório de auditoria.

Explicação das linhas (adaptado da norma ISO
9000:1999)
Relação associativa, não hierárquica
Relação hierárquica (conceito inferior é
parte do conceito superior)

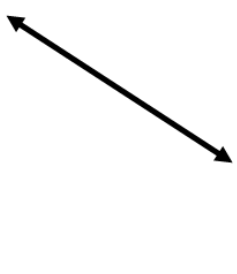

\section{AÇÕES CORRETIVAS / \\ PREVENTIVAS}

Processo de eliminar a causa de uma não conformidade existente ou potencial, que é iniciado como resultado da auditoria.

Fonte: Karapetrovic e Willborn (2000, p. 286). Tradução do autor. 


\subsection{Definições de Processo}

Hammer (2001) define processo como um grupo organizado de atividades correlatas que juntas transformam um ou mais tipos de inputs em outputs que têm valor para o cliente.

A definição de Hammer comunica algumas idéias essenciais:

- Um processo consiste em um grupo de atividades e não apenas em uma única atividade.

- As atividades que fazem um processo não são aleatórias ou casuais. Elas são relacionadas e organizadas.

- Todas as atividades de um processo devem trabalhar juntas em prol de um objetivo comum.

- Processos existem para criar resultados que representem valor para os clientes, não importando se estes são internos (como outros departamentos de uma organização) ou externos (organizações ou consumidores finais).

Um processo pode ser visto como uma cadeia de valor, na qual cada atividade ou etapa contribui para um resultado final. Algumas atividades agregam valor de forma direta, enquanto outras podem não agregar valor.

Todas as atividades consomem recursos da empresa e o desafio dos gestores é eliminar etapas que não adicionem valor e ao mesmo tempo buscar aumentar a efetividade das etapas que agreguem valor (HAMMER, 2001)

Gardner (2004) propõe, através da Figura 4, um modelo para ilustrar um processo.

Figura 4 - Modelo de Processo de Gardner

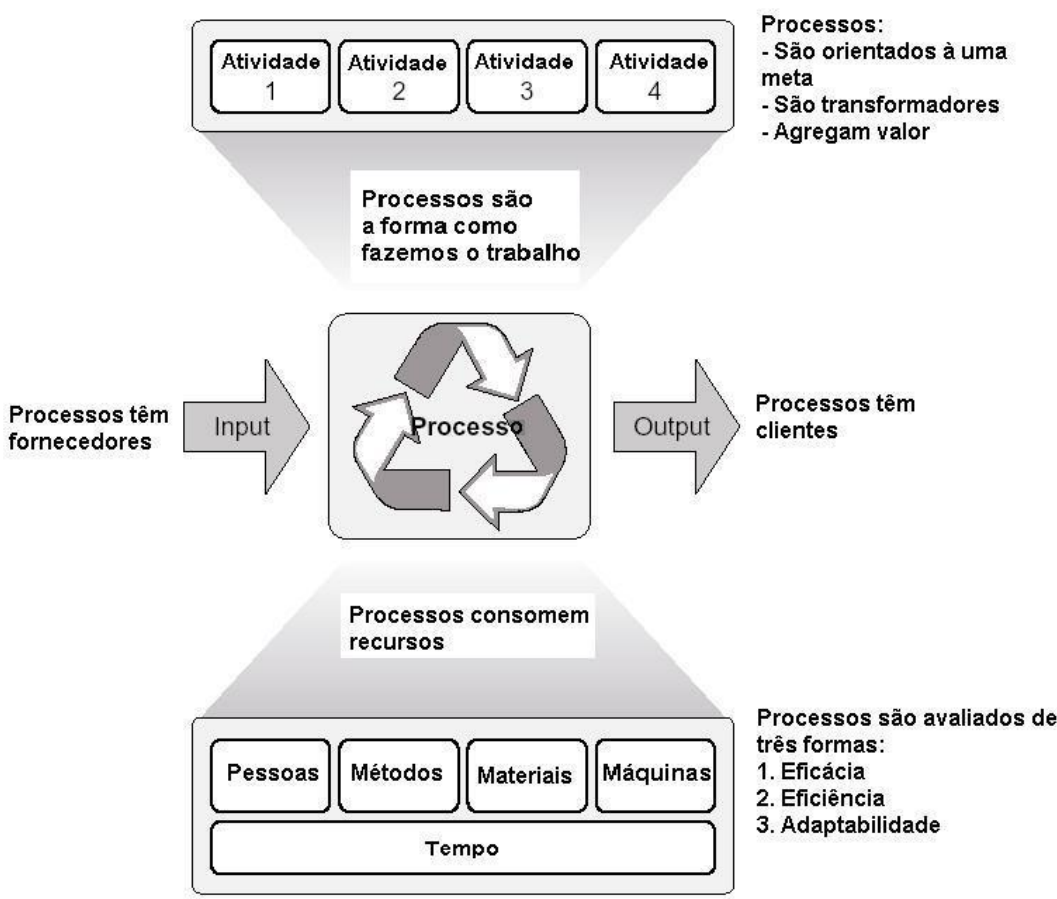

Fonte: Gardner (2004, p. 29). Tradução do autor. 
O modelo de Gardner cita eficácia, eficiência e adaptabilidade como formas sob as quais os processos são avaliados. O termo adaptabilidade significa capacidade de se ajustar para um novo uso ou condição. Beckmerhagen et al (2004) afirmam que a eficácia pode ser definida como a realização do que foi planejado e a eficiência como a relação entre o resultado obtido e os recursos utilizados. Os autores ressaltam que estes dois aspectos são independentes e podem ser medidos separadamente.

Na parte superior do modelo de Gardner (2004) aparecem as atividades, ou seja, como o trabalho é feito. Na parte inferior são representados os recursos consumidos ou utilizados na realização do trabalho. Por exemplo: em uma auditoria são utilizados recursos materiais como computadores, recursos humanos como o auditor e a equipe de auditados. Em uma auditoria também são consumidos recursos como tempo e dinheiro, haja vista que as pessoas e recursos envolvidos poderiam estar sendo utilizados para outros fins, tal como a produção de peças para a venda. Uma adaptação do modelo de Gardner (2004), voltada para o processo de auditoria, é apresentada na Figura 5.

Figura 5 - Modelo de Processo de Auditoria

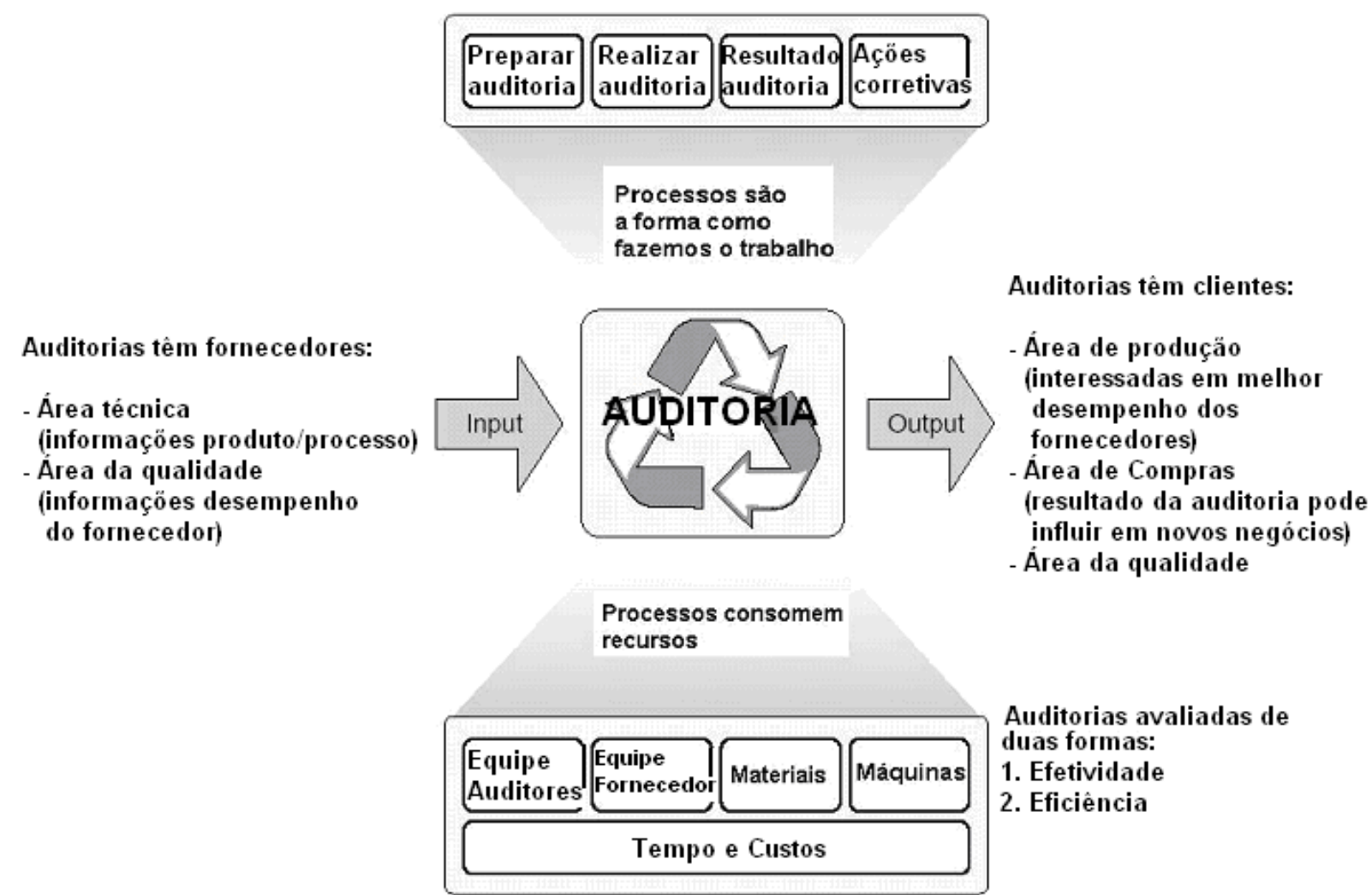

Fonte: Adaptado pelo autor a partir de GARDNER (2004, p. 29).

Uma outra definição de processo, mais simplificada que a de Gardner (2004), e inserida no contexto de auditoria da qualidade, é apresentada por Liebesman (2009): 
Mas o que é um processo? Neste contexto é uma transformação de inputs em outputs que é limitada pelos controles (controls) e recursos (resources) aplicados. Consideremos a produção de placas de circuito impresso. O processo transforma matérias-primas tais como componentes e placas de circuito. O processo é limitado por controles, tais como a temperatura do banho de solda, velocidade da linha de produção, seqüências de testes, inserção de componentes e recursos que incluem componentes, circuitos, pessoal qualificado e equipamentos de produção (LIEBESMAN, 2009, p. 60).

Liebesman (2009) apresenta graficamente sua definição de processo na Figura 6.

Figura 6 - Modelo de Processo de Liebesman

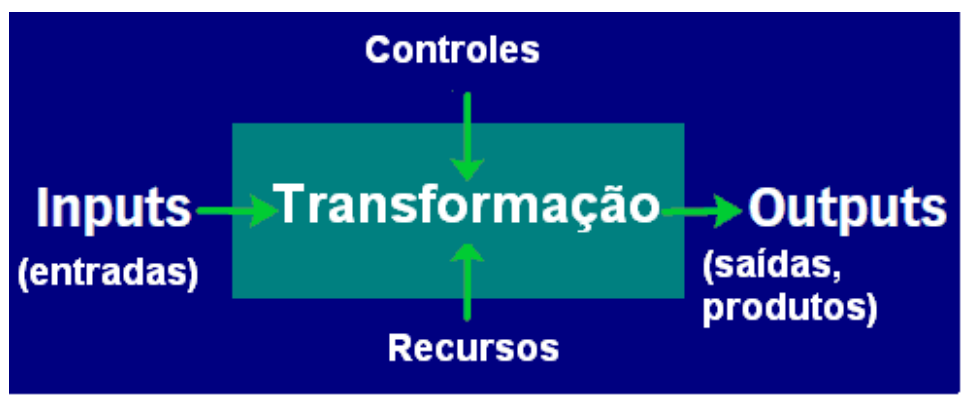

Fonte: LIEBESMAN (2009, p. 60) tradução do autor.

Russell (2007) apresenta um modelo de processo de auditoria com destaque para a necessidade de follow-up, ou seja, da definição e acompanhamento das ações corretivas ou preventivas cujo objetivo é o de eliminar as causas das não conformidades encontradas na auditoria.

Figura 7 - Modelo de Processo de Auditoria

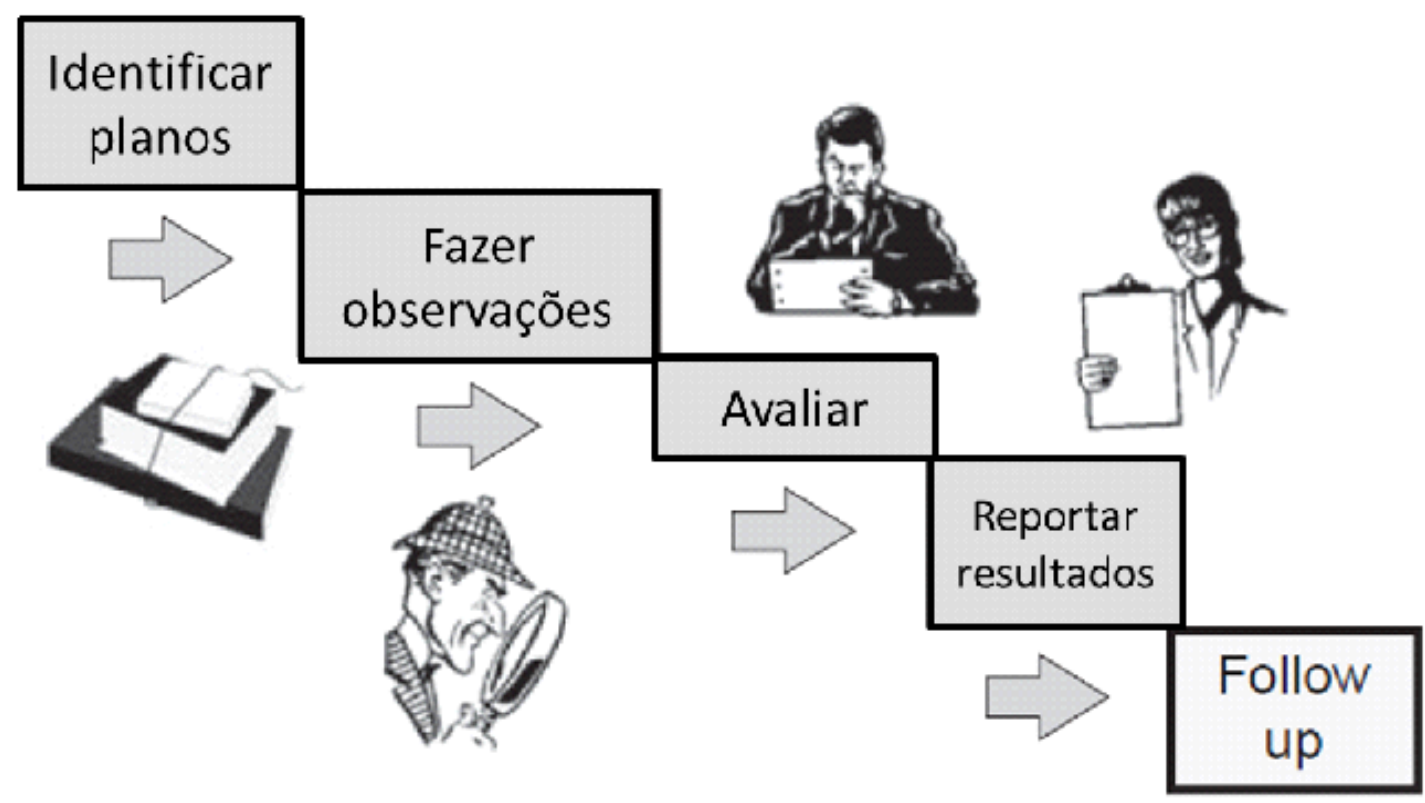

Fonte: RUSSELL (2007, p. 3) tradução do autor.

Os conceitos de processo foram apresentados como elementos introdutórios do conceito de efetividade da auditoria. Os modelos de Gardner (2004), Liebesman (2009) e Russell (2007) podem ser usados para estruturar a auditoria como um processo, identificando recursos, atividades e controles que influenciem diretamente sua efetividade. O conceito de efetividade é apresentado no 
item 2.6, juntamente com uma revisão da literatura sobre o tema, que fornecerá as bases para identificação de fatores essenciais à efetividade da auditoria.

\title{
2.6 A efetividade da auditoria no processo de melhoria contínua
}

O dicionário CEGALLA da Língua Portuguesa (2008) define efetivo (adjetivo) como algo eficaz, que produz efeito. O WEBSTER'S New Dictionary of the English Language (2002) define effective como um adjetivo de algo que produz um forte ou desejado efeito. Assim, os termos efetivo e efetividade foram considerados mais adequados como tradução dos vocábulos effective e effectiveness comumente encontrados na literatura acadêmica disponível em inglês.

Em meados de 2004, ainda sob os impactos da quebra da ENRON, Beckmerhagen et al. publicaram estudos de caso focados na efetividade de auditorias da qualidade. Um parágrafo da introdução de seu trabalho condensa a "fama" da auditoria:

\begin{abstract}
A palavra 'auditoria' nunca teve uma conotação positiva em empresas do mundo afora. Marcadas pela percepção de que apenas executam o 'mal necessário' da verificação de conformidade, auditorias financeiras e mesmo as da qualidade estão acuadas para provar ao cliente que são efetivas e adicionam valor ao negócio. Mas provavelmente nada preparou a profissão de auditor para o recente fiasco no caso de uma grande empresa de energia norteamericana (BECKMERHAGEN et al 2004, p.14).
\end{abstract}

A ENRON foi uma grande companhia de energia norte-americana que quebrou em 2001 após um escândalo de "maquiagem" dos números financeiros da empresa, que deixou 21.000 empregados sem trabalho e mais de 30 bilhões de dólares em dívidas, além da perda total do valor de suas ações para os investidores. O fato foi amplamente divulgado pela imprensa internacional. Informações obtidas em <http://news.bbc.co.uk/2/hi/business/3398913.stm>， acesso em 20/01/2013.

O termo "mal necessário" utilizado por Beckmerhagen et al. (2004) pode ser relacionado ao tema apontado por Power e Terziovski (2006): a tônica da condução de uma auditoria da qualidade. Os autores assinalam que uma auditoria pode ser conduzida com foco na melhoria contínua ou simplesmente na conformidade que, neste caso, é entendida como controle do cumprimento de requisitos.

A revisão da literatura destacou diferentes correntes de pensamento sobre a condução geral de auditorias não-financeiras e o papel do auditor não-financeiro. Há um tema recorrente na literatura onde o auditor não financeiro deve focar na melhoria contínua ao invés de focar na conformidade. Por outro lado, há também a visão de que este é um papel do auditor interno como parte do processo de auditoria interna, enquanto o auditor externo deve focar primeiramente nas normas (POWER E TERZIOVSKI, 2006, p.129).

O auditor externo citado por Power e Terziovski (2006) é o auditor de terceira parte, especificamente auditores de certificação conforme norma ISO 9000, enquanto o auditor interno é o auditor da própria organização. 
A condução de uma auditoria da qualidade com foco na melhoria contínua, apresentada por Power e Terziovski (2006), é usada como referência neste trabalho, onde é pesquisada a auditoria realizada por auditores de montadoras, ou de segunda parte, conforme descrito por Arter (2003). Desta forma, uma auditoria efetiva pode ser entendida como uma auditoria que produza efeito positivo na melhoria contínua dos processos auditados, não estando limitada a apenas identificar não conformidades com base em determinada norma.

Beckmerhagen et al (2004) definiram, baseados em Karapetrovic e Willborn (2000), cinco fatores que uma auditoria deve possuir para que a mesma possa ser considerada efetiva:

- Adequação: que alcance os objetivos pré-estabelecidos dentro de um escopo definido, que seja adequada à situação e resposta necessárias no momento de sua realização;

- Confiabilidade: que não falhe no cumprimento de sua função, que produza resultados e achados confiáveis e relevantes para a melhoria contínua;

- Disponibilidade: que a auditoria possa ocorrer quando necessária, seja conforme planejamento prévio ou no atendimento de uma prioridade não planejada;

- Manutenabilidade: que se pode manter, capaz de voltar imediatamente à operação após detecção de uma falha grave na condução da auditoria ou do processo auditado e;

- Validade: que traga satisfação e adicione valor às partes interessadas.

Karapetrovic e Willborn (2000), em seu estudo sobre efetividade de sistemas de auditoria, dão destaque a três dentre os cinco fatores descritos acima: confiabilidade, disponibilidade e adequação. Os autores afirmam que a confiabilidade pode ser afetada por inúmeros erros de auditoria, apresentados abaixo e seguidos de observações ou definições quando aplicável:

a) Erros nas fases de planejamento das auditorias: o planejamento é uma fase essencial na realização de qualquer tipo de auditoria (MUNRO 2003, NBR ISO 19011 2002, BECKMERHAGEN et al. 2004);

b) Uso de auditores não qualificados ou incompetentes para conduzir uma auditoria: a qualificação e competência dos auditores têm ligação direta com a efetividade da auditoria, pois esta depende do fator humano para alcançar seus objetivos, conforme Karapetrovic e Willborn (2000);

c) Falta de reuniões de abertura ou fechamento: estas reuniões fazem parte do procedimento típico das auditorias (NBR ISO 19011, 2011);

d) Uso impróprio ou inadequado de métodos de amostragem e outras técnicas de auditoria durante a coleta das evidências: evidências de auditoria podem ser registros, apresentação de fatos ou outras informações analisadas com base em critérios de auditoria, que são políticas, procedimentos ou requisitos aplicáveis à uma determinada auditoria (NBR ISO 19011, 2011); 
e) Quantidade insuficiente de evidências;

f) Verificação deficiente (ou inexistente) das evidências coletadas;

g) Avaliação tendenciosa de evidência de auditoria com relação ao critério de auditoria;

h) Inconsistências nas evidências e fatos coletados na auditoria;

i) Aceitação de um sistema de gerenciamento da qualidade ineficaz ou não conforme (em auditorias de certificação);

j) Rejeição de um sistema de gerenciamento da qualidade eficaz ou conforme (em auditorias de certificação);

k) Relatório de auditoria tendencioso, subjetivo ou indevidamente influenciado.

Com exceção dos itens descritos nas alíneas “j” e "k”, diretamente ligados às auditorias de certificação, os demais erros listados por Karapetrovic e Willborn (2000) são usados como base no instrumento de pesquisa deste trabalho, bem como as características essenciais apresentadas por Beckmerhagen et al (2004): confiabilidade, adequação, manutenabilidade, validade e disponibilidade; diretamente ligadas à efetividade das auditorias segundo os autores. Os usos dos erros de auditoria e das características essenciais à efetividade da mesma no instrumento de pesquisa estão ligados aos conceitos de processo já apresentados no referencial teórico. Os erros e características podem ser relacionados às atividades e recursos do processo de auditoria, conforme modelos de Gardner (2004) e Liebesman (2009), apresentados no item 2.4.

O foco na melhoria contínua, descrito por Power e Terziovski (2006), é usado neste trabalho para caracterizar uma auditoria como efetiva.

A auditoria realizada pelas montadoras, como ferramenta de melhoria contínua da qualidade, está inserida na relação entre comprador (montadora) e fornecedor (autopeças). De acordo com Wong (2002), o número de empresas que adotam uma relação de cooperação com os fornecedores tem aumentado. Entretanto, mesmo as relações de cooperação passam por momentos de stress relacional, que é definido por Zhang, Henke e Griffith (2009) como a pressão experimentada por um fornecedor devido a requisitos de produto ou mesmo expectativas "difíceis de alcançar" que são estipulados pelos compradores. Deste modo, é cabível inferir que o "momento" de execução da auditoria pode influenciar em sua efetividade.

Além do momento específico de stress relacional, é relevante afirmar que asseguramento da qualidade dos fornecedores (realizado pelas montadoras) é composto de diferentes fases, e estruturado de forma diferente pelas montadoras. Abaixo segue um modelo macro, o AQF (Assurance Qualité Fournisseur) definido pela PSA Peugot-Citroën, que será usado como referência neste estudo. 


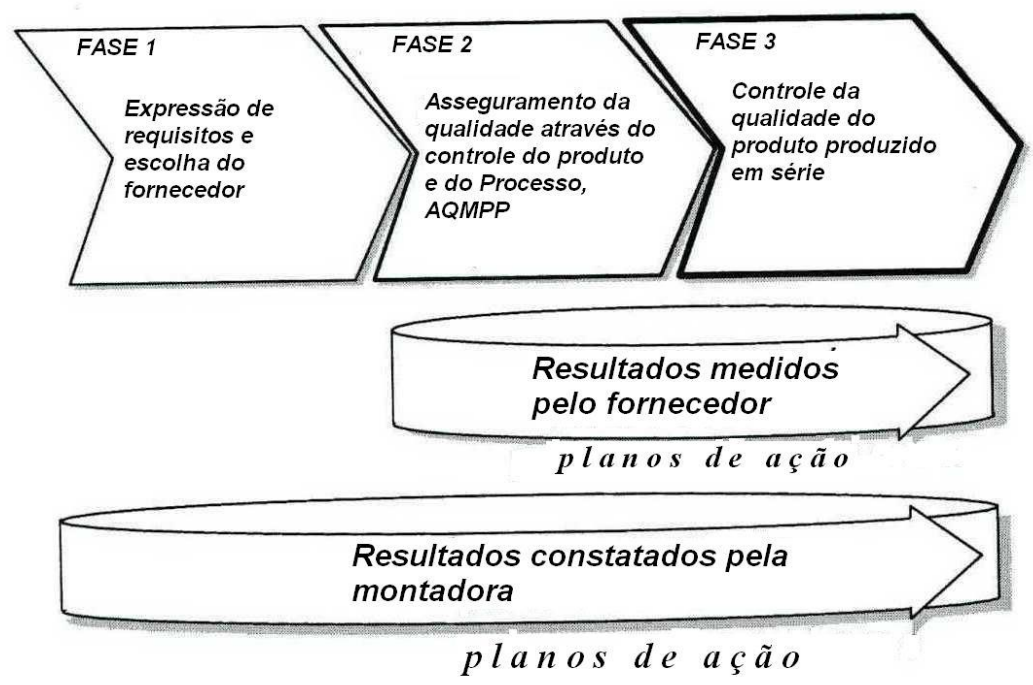

Fonte: PSA Q620450 (1999, p.3). Tradução do autor.

A fase do stress relacional pode também ser representada pelos momentos de crise da qualidade, que se enquadram na fase três do $\mathrm{AQF}$, porém, representam momentos singulares da relação entre montadora e fornecedor durante o controle da qualidade na produção em série, pois nas crises da qualidade os fornecedores estão sob pressão devido a não entrega de produtos com os requisitos da qualidade conforme especificado pela montadora, situação que se encaixa na descrição de Zhang, Henke e Griffith (2009). As crises da qualidade podem ser caracterizadas por momentos onde a quantidade de defeitos é muito grande ou os defeitos de peças de determinado fornecedor são graves e representam riscos de segurança ou recall, procedimento onde uma montadora convoca clientes a retornarem com seus carros para a troca de peças em concessionários da marca. Recalls são normalmente ligados a riscos de segurança.

Deste modo, este estudo vai considerar quatro momentos distintos para a aplicação de auditorias:

1. Escolha do fornecedor

2. Desenvolvimento do processo

3. Dia a dia da produção em série

4. Crises da qualidade

\section{Método}

Conforme descrito por Vergara (2009), a pesquisa ora apresentada é exploratória porque possui natureza de sondagem que não comporta hipóteses em seu projeto inicial, embora as mesmas possam aparecer ao final da mesma. Também é descritiva, pois busca expor características de determinada população ou fenômeno, sem, contudo ter o compromisso de explicar este último. 
Trata-se de uma pesquisa de campo devido ao fato de investigar o fenômeno onde o mesmo acontece, ou seja, nas plantas dos fornecedores.

Complementado a classificação de exploratória, descritiva e pesquisa de campo, descrita por Vergara (2009), é relevante citar o método de pesquisa do tipo survey, descrita por Malhotra e Grover (1998), que possui as seguintes características:

- Solicita a informação a determinado grupo;

- Utiliza um instrumento de pesquisa estruturado para coleta de dados, e

- A informação é coletada através de uma amostra.

Foram utilizados questionários, enviados por e-mail, para a coleta dos dados.

A pesquisa ocorreu entre maio de 2010 e fevereiro de 2011. Os questionários foram enviados e respondidos no primeiro bimestre de 2011.

O questionário foi elaborado de modo a prover as informações necessárias para responder às perguntas de pesquisa e cumprir os objetivos do trabalho. Foram incluídas instruções definidas e notas explicativas conforme recomendado em Marconi e Lakatos (2008), também foram utilizadas colocações quantitativas, tais como "menos de 50\% dos casos" para evitar ambigüidades, conforme Wright e Giovinazzo (2000).

\subsection{Estrutura do instrumento de pesquisa}

O questionário tem um total de vinte e uma perguntas, sendo nove perguntas fechadas e doze perguntas abertas. É relevante ressaltar que, dentre as doze perguntas abertas, oito perguntas solicitavam apenas que os respondentes citassem ou listassem informações sem a necessidade de argumentação. Em quatro das vinte e uma perguntas eram solicitados argumentos dos respondentes.

Uma relação entre as perguntas do questionário, conceitos-chave, objetivos e questões de pesquisa é apresentada no Quadro 2. Os espaços em branco no quadro citados podem ser justificados, por exemplo, pelo fato que determinadas questões são relacionadas apenas ao referencial teórico e, portanto, não foram repassadas ao questionário. 
Quadro 2 - Relação das perguntas do questionário com objetivos, questões e conceitos da pesquisa

\begin{tabular}{|c|c|c|c|c|}
\hline \multicolumn{2}{|c|}{ OBJETIVOS DA PESQUISA } & \multirow{2}{*}{ QUESTÃO } & \multirow{2}{*}{$\begin{array}{l}\text { QUESTÕES } \\
\text { DA } \\
\text { PESQUISA }\end{array}$} & \multirow{2}{*}{ CONCEITOS CHAVE } \\
\hline GERAL & ESPECÍFICOS & & & \\
\hline \multirow{10}{*}{$\begin{array}{c}\text { Como } \\
\text { aumentar a } \\
\text { efetividade } \\
\text { das auditorias } \\
\text { da qualidade } \\
\text { realizadas por } \\
\text { montadoras } \\
\text { no processo } \\
\text { de melhoria } \\
\text { contínua dos } \\
\text { fornecedores }\end{array}$} & $\begin{array}{l}\text { Identificar pontos fracos; } \\
\text { características essenciais } \\
\text { menos percebidas. }\end{array}$ & 14,15 & \multirow{2}{*}{$\begin{array}{l}\text { O que mais } \\
\text { tem } \\
\text { prejudicado a } \\
\text { efetividade da } \\
\text { auditoria? }\end{array}$} & $\begin{array}{l}\text { Características essenciais } \\
\text { para efetividade da } \\
\text { auditoria. } \\
\text { (BECKMERHAGEN et al. } \\
\text { 2004) }\end{array}$ \\
\hline & $\begin{array}{l}\text { Identificar pontos fracos; } \\
\text { erros mais percebidos. }\end{array}$ & 12,13 & & $\begin{array}{l}\text { Erros de auditoria. } \\
\text { (KARAPETROVIC e } \\
\text { WILLBORN, 2002) }\end{array}$ \\
\hline & \multirow[b]{3}{*}{ 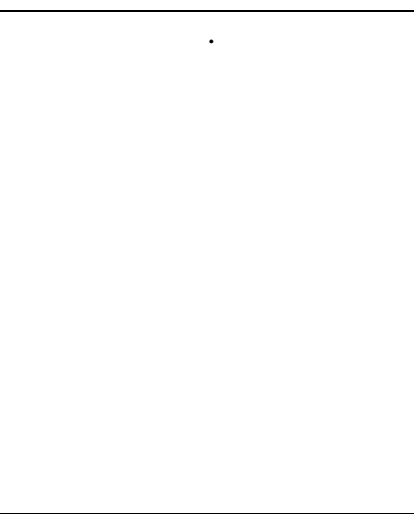 } & & $\begin{array}{l}\text { Há pontos de } \\
\text { consenso? }\end{array}$ & $\begin{array}{l}\text { Tabulação conforme } \\
\text { Wright e Giovinazzo } \\
(2000)\end{array}$ \\
\hline & & & $\begin{array}{l}\text { O que é } \\
\text { auditoria? }\end{array}$ & $\begin{array}{l}\text { Definição de auditoria } \\
\text { (MUNRO, 2003) }\end{array}$ \\
\hline & & & $\begin{array}{l}\text { O que é } \\
\text { efetividade da } \\
\text { auditoria? }\end{array}$ & $\begin{array}{l}\text { Efetividade da auditoria } \\
\text { (BECKMERHAGEN et al. } \\
\text { 2004; KARAPETROVIC e } \\
\text { WILLBORN, 2002; } \\
\text { POWER e TERZIOVSKI, } \\
\text { 2006) }\end{array}$ \\
\hline & $\begin{array}{l}\text { Identificar tipos de } \\
\text { auditoria que mais } \\
\text { contribuem para melhoria } \\
\text { contínua }\end{array}$ & 18 & & $\begin{array}{l}\text { Tipos de auditoria } \\
\text { (SILVA, 2009; ARTER, } \\
2003 \text { e RUSSELL, 2007) }\end{array}$ \\
\hline & & \multirow{2}{*}{$10,1117,20$} & $\begin{array}{l}\text { A auditoria é } \\
\text { efetiva? }\end{array}$ & \multirow{2}{*}{$\begin{array}{l}\text { Efetividade da auditoria } \\
\text { (BECKMERHAGEN et al. } \\
\text { 2004; KARAPETROVIC e } \\
\text { WILLBORN, 2002; } \\
\text { POWER e TERZIOVSKI, } \\
\text { 2006) }\end{array}$} \\
\hline & & & $\begin{array}{l}\text { Quão efetiva } \\
\text { é a auditoria? }\end{array}$ & \\
\hline & $\begin{array}{l}\text { Verificar em qual fase do } \\
\text { asseguramento da qualidade } \\
\text { a auditoria é mais efetiva. }\end{array}$ & 19 & $\begin{array}{l}\text { Quando uma } \\
\text { auditoria } \\
\text { deve ser } \\
\text { realizada? }\end{array}$ & $\begin{array}{l}\text { Asseguramento da } \\
\text { Qualidade de Fornecedores } \\
\text { (conforme descrito em } \\
\text { norma da PSA) }\end{array}$ \\
\hline & $\begin{array}{l}\text { Verificar quais montadoras } \\
\text { influenciaram as respostas } \\
\text { (objetivo ligado à } \\
\text { delimitação do estudo) }\end{array}$ & 6 & & $\begin{array}{l}\text { Definição de tipos de } \\
\text { auditoria (ARTER, 2003; } \\
\text { RUSSELL, } 2007 \text { e SILVA, } \\
\text { 2009) }\end{array}$ \\
\hline
\end{tabular}

Fonte: Autoria própria (2011)

\subsection{Validação do instrumento de pesquisa}

Foi elaborada uma versão "piloto" do questionário, que foi validada com um pré-teste.

O pré-teste foi realizado com quatro profissionais da área, sendo três deles também acadêmicos e nenhum fez parte da amostra. O pré-teste resultou em alterações no texto das questões, em dois eixos principais: facilitar a compreensão e deixar claro que estava sendo pesquisada a opinião dos pesquisados e não o seu conhecimento da teoria sobre qualidade. 


\subsection{Características do Universo e da Amostra}

A amostra contou apenas com profissionais experientes, que tenham contato direto com os auditores, dependendo da estrutura de cada organização, incluindo gerentes, coordenadores e analistas.

A amostra não é probabilística, devido à impossibilidade de se escolher aleatoriamente fornecedores para responder os questionários, haja vista que nem todos os profissionais se dispõem a tal. Desta forma, foram enviados os questionários para os fornecedores, acompanhados de um email que pedia a sua colaboração com a pesquisa.

A amostra foi composta por fornecedores de autopeças de uma montadora de veículos comerciais. A empresa possui um total de 305 fornecedores de autopeças, que correspondem ao universo da amostra, dos quais foi retirado um estrato de 83, dos mais relevantes em termos de faturamento dentro de diferentes grupos de peças (metálicas, conjunto motor, acabamento e peças elétricas). Foram enviados questionários as representantes de cada um destes fornecedores, obtendo-se 14 falhas de entrega, ou seja, o questionário foi efetivamente recebido por 69 fornecedores. O total de questionários respondidos foi 19 , que representa $27,5 \%$ de respostas e $6,2 \%$ do total de fornecedores. Marconi e Lakatos (2008) assinalam que, em média, os questionários alcançam $25 \%$ de devolução. Portanto, o resultado de 27,5\% coloca esta pesquisa ligeiramente acima da média indicada por Marconi e Lakatos (2008).

O fato da amostra não ser probabilística determina que o uso dos resultados para uma inferência sobre a população (especialistas de fornecedores) não é sustentável, e que generalizações devem ser feitas com cautela, conforme Anderson, Sweeney e Williams (2008).

Embora não probabilística, pode-se ter uma idéia da representatividade da amostra considerando que $27,5 \%$ dentre os mais relevantes fornecedores da empresa, responderam à pesquisa.

\section{Resultados e Discussão}

Os respondentes tiveram o anonimato garantido, portanto, os resultados apresentados não permitem a identificação dos mesmos.

Os resultados da pesquisa são apresentados com técnicas de estatística descritiva. Estatística é definida como "a arte e ciência de coletar, analisar, apresentar e interpretar dados" (ANDERSON, SWEENEY e WILLIAMS, 2008, p.14). Os mesmos autores acrescentam que a estatística descritiva compreende sumários de dados tabulares, gráficos ou numéricos.

Respostas de perguntas que solicitavam argumentos ou justificativas dos pesquisados foram separadas em grupos, conforme Estes e Kuespert (1976) apud Wright e Giovinazzo (2000). 


\subsection{Perfil dos Respondentes}

Os respondentes compõem um grupo de profissionais experientes, conforme demonstrado na Tabela 1.

Tabela 1 - Experiência profissional dos respondentes (anos)

\begin{tabular}{cccc}
\hline $\begin{array}{c}\text { TEMPO DE EXPERIÊNCIA PROFISSIONAL } \\
\text { Mínimo }\end{array}$ & Máximo & Média & Mediana \\
\hline 5,0 & 41,0 & 21,9 & $\mathbf{2 0 , 0}$ \\
& & & \\
$\begin{array}{c}\text { TEMPO NO CARGO ATUAL } \\
\text { Mínimo }\end{array}$ & Máximo & Média & Mediana \\
\hline 0,3 & 15,0 & 6,8 & $\mathbf{6 , 0}$ \\
\hline Fonte: Pesquisa de campo (2011) & & &
\end{tabular}

A maioria ocupa cargos de liderança, conforme Tabela 2.

Tabela 2 - Cargos dos respondentes

\begin{tabular}{lc}
\hline CARGO & PERCENTUAL \\
\hline Gerente & $\mathbf{4 2 , 1}$ \\
Assessor Gerente & $\mathbf{5 , 3}$ \\
Coordenador & $\mathbf{5 , 3}$ \\
Supervisor & $\mathbf{5 , 3}$ \\
Chefe & $\mathbf{5 , 3}$ \\
Analista & 31,6 \\
Engenheiro & 5,3 \\
\hline Fonte: Pesquisa de campo (2011)
\end{tabular}

Mais de 70\% dos respondentes são da área da Qualidade, vide Tabela 3.

Tabela 3 - Área de atuação dos respondentes

\begin{tabular}{lc}
\hline ÁREA & PERCENTUAL \\
\hline Qualidade & $\mathbf{7 2 , 2}$ \\
Sistema de Gestão & 5,6 \\
Industrial & 11,1 \\
Programas & 5,6 \\
Comercial & 5,6 \\
\hline
\end{tabular}

Fonte: Pesquisa de campo (2011)

A questão 5 perguntava se os pesquisados já haviam sido auditados e, caso afirmativo, em quais tipos de auditoria (primeira, segunda e terceira partes). A resposta foi de sim para 100\% dos casos em todos os tipos de auditoria.

Além de "auditados", mais de $90 \%$ dos pesquisados possui também experiência como auditor. Esta informação pode ser usada como indicativo de que a auditoria, como ferramenta de 
melhoria contínua da qualidade, é conhecida dos pesquisados, seja como auditados ou como auditores. A questão 7 pergunta se o pesquisado já havia realizado auditorias. Os resultados são apresentados no Gráfico 1.

Gráfico 1 - Experiência dos pesquisados como auditores

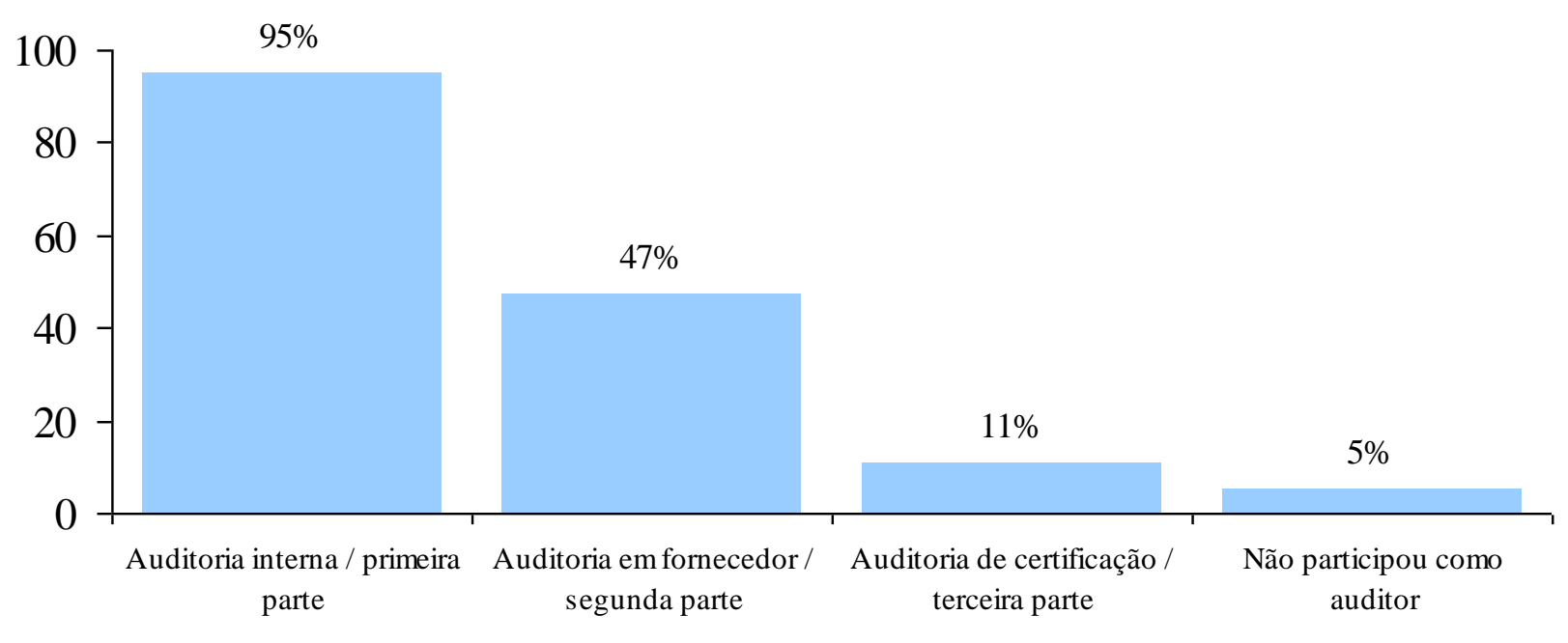

Fonte: Pesquisa de campo (2011)

\subsection{Perfis das Empresas Pesquisadas}

As empresas pesquisadas são fornecedores diretos (ou tier 1) de uma montadora. São empresas com departamentos da qualidade estruturados e que possuem certificação conforme ISO/TS 16949:2009, comumente exigida por montadoras. Além desta certificação, outras certificações foram citadas pelos respondentes, com destaque para a certificação ISO 14001, voltada ao meio ambiente, conforme Tabela 4.

\begin{tabular}{lc}
\multicolumn{2}{c}{ Tabela 4 - Certificações das empresas pesquisadas } \\
\hline CERTIFICAÇÃO & PERCENTUAL \\
\hline ISO/TS 16949:2009 & $\mathbf{1 0 0 , 0}$ \\
ISO 14001:2004 & $\mathbf{7 8 , 9}$ \\
OHSAS 18001:2007 & $\mathbf{2 6 , 3}$ \\
ISO 9001:2008 & 31,6 \\
VDA & 10,5 \\
QSB & 5,3 \\
Q1 FORD & 5,3 \\
\hline
\end{tabular}

Fonte: Pesquisa de campo (2011)

As empresas pesquisadas estão concentradas no estado de São Paulo, conforme Tabela 5.

Tabela 5 - Localização das empresas pesquisadas

\begin{tabular}{lc}
\hline REGIÃO & PERCENTUAL \\
\hline Grande SP & $\mathbf{4 2 , 1}$ \\
Interior SP & $\mathbf{4 2 , 1}$ \\
SC (interior) & 5,3 \\
RJ (interior) & 5,3 \\
RS (interior) & 5,3 \\
\hline \multicolumn{2}{l}{ Fonte: Pesquisa de campo (2011) }
\end{tabular}




\subsection{Escopo da Pesquisa / Experiência Relativa à Auditorias de Montadoras}

Conforme citado no item sobre metodologia, esta pesquisa não visa uma norma ou montadora específica. Desta forma, os respondentes foram instados a responder conforme sua opinião e experiência com auditorias de diferentes montadoras. A questão 6 tem o seguinte texto: “Já participou de auditorias feitas por montadoras? Cite as montadoras abaixo".

As respostas, que podem ser usadas como indicativo do escopo, ou seja, de quais normas e montadoras influenciaram os pesquisados estão na Tabela 6 .

Tabela 6 - Auditorias atendidas pelos respondentes

\begin{tabular}{lc}
\hline MONTADORA & PERCENTUAL \\
\hline Ford & $\mathbf{6 8 , 4}$ \\
Volkswagen & $\mathbf{6 3 , 2}$ \\
MAN Latin America & $\mathbf{5 7 , 9}$ \\
General Motors & $\mathbf{5 2 , 6}$ \\
Mercedes-Benz & $\mathbf{4 7 , 4}$ \\
Volvo & $\mathbf{4 7 , 4}$ \\
Renault & $\mathbf{3 6 , 8}$ \\
Scania & $\mathbf{3 1 , 6}$ \\
Fiat & 21,1 \\
PSA Peugeot Citroën & 21,1 \\
Toyota & 15,8 \\
International/MWM/Navistar & 10,5 \\
Iveco & 10,5 \\
AGCO & 5,3 \\
John Deere & 5,3 \\
CNH & 5,3 \\
Honda & 5,3 \\
Mitsubishi & 5,3 \\
Komatsu & 5,3 \\
Agrale & 5,3 \\
Não participou & 0,0 \\
Moto Honda & 0,0 \\
Nissan & 0,0 \\
\hline Fonte: Pesquisa de campo (2011) &
\end{tabular}

Este resultado mostra que as opiniões são influenciadas por mais de uma montadora, com forte participação das grandes produtoras de caminhões (MAN, Mercedes-Benz, Ford, Volvo e Scania) e também das fabricantes de veículos General Motors, Ford e Volkswagen. Outro ponto de destaque é a baixa influência da Fiat, líder do mercado nacional de carros (ANFAVEA, 2010), citada por apenas $21 \%$ dos pesquisados. 


\subsection{Efetividade das Auditorias}

A pergunta 10 apresenta o seguinte texto: "De uma forma geral, você considera que as auditorias (feitas pelos clientes) contribuem de forma efetiva na melhoria contínua da qualidade?”. As respostas aparecem na Tabela 7.

Tabela 7 - Contribuição das auditorias na melhoria contínua da qualidade

\begin{tabular}{lc}
\hline & PERCENTUAL \\
\hline $\begin{array}{l}\text { Sim, sempre ou quase sempre (75 a } \\
100 \% \text { dos casos) }\end{array}$ & $\mathbf{5 2 , 6}$ \\
\hline $\begin{array}{l}\text { Sim, na maioria das vezes (50 a } \\
74 \% \text { dos casos) }\end{array}$ & $\mathbf{3 6 , 8}$ \\
\hline $\begin{array}{l}\text { Sim, poucas vezes (25 a 49\% dos } \\
\text { casos) }\end{array}$ & 10,5 \\
\hline $\begin{array}{l}\text { Não, nunca ou quase nunca (menos } \\
\text { de 25\% dos casos) }\end{array}$ & 0,0 \\
\hline Fonte: Pesquisa de campo (2011)
\end{tabular}

É percebida uma concentração de quase $90 \%$ das respostas entre as opções "na maioria das vezes" e "sempre ou quase sempre". Portanto, pode-se considerar que as auditorias contribuem de forma efetiva na melhoria da qualidade.

A melhoria contínua é um dos objetivos primários das auditorias segundo Karapetrovic e Willborn (2000).

Foram também solicitados dois argumentos (ou exemplos recorrentes) que serviram de base para a resposta escolhida. As citações foram breves e buscou-se comparar os motivos que levaram à resposta "sempre ou quase sempre" (52\%) com os que levaram à resposta "poucas vezes" (10\%)

\section{Sim, sempre ou quase sempre ( 75 a $100 \%$ dos casos)}

Boa parte dos pesquisados que escolheu esta opção afirmava que a auditoria levantava potenciais de melhoria que dificilmente seriam detectados por quem está inserido no dia a dia do processo produtivo.

Outros dois argumentos também merecem destaque:

a) A auditoria de cliente "acelera" a implementação de ações corretivas porque sensibiliza mais a direção da empresa que uma auditoria interna, dada a importância da relação clientefornecedor.

b) A auditoria de cliente possibilita a realização de benchmarking, com a proposição de ações de melhoria pelo cliente. Isso ocorre porque a montadora tem interesse direto na melhoria dos processos de seus fornecedores, algo que não é necessariamente verdade quando da realização de uma auditoria de terceira parte, onde o auditor tem o foco voltado para a verificação da conformidade. 


\section{Sim, poucas vezes ( 25 a $49 \%$ dos casos)}

Os respondentes que marcaram esta opção centraram seus argumentos na falta de preparo e embasamento dos auditores e no acompanhamento das auditorias. Estes pontos foram apresentados no referencial teórico e serão discutidos na análise da questão 12.

\subsection{Melhor Momento Para Realizar Uma Auditoria}

A pergunta de número 19 era: "Em qual das fases do relacionamento montadora/fornecedor (citadas abaixo) a auditoria da montadora se mostra mais efetiva para a melhoria contínua?"..

Esta questão e outras voltadas a particularidades da indústria automobilística foram incluídas porque o setor industrial no qual a auditoria se insere representa papel importante nos riscos referentes à efetividade da mesma, conforme Beckmerhagen et al (2004).

As respostas estão na Tabela 8 .

Tabela 8 - Quando as auditorias de montadoras mais contribuem para a melhoria da qualidade

\begin{tabular}{lc}
\hline & PERCENTUAL \\
\hline $\begin{array}{l}\text { Antes da emissão do pedido } \\
\text { (durante o processo de escolha do } \\
\text { fornecedor) }\end{array}$ & 26,3 \\
\hline $\begin{array}{l}\text { Dia a dia da produção em série } \\
\text { (melhoria contínua) }\end{array}$ & 31,6 \\
\hline Desenvolvimento do processo & 42,1 \\
\hline Crises de qualidade & $\mathbf{0 , 0}$ \\
\hline Fonte: Pesquisa de campo (2011)
\end{tabular}

Fonte: Pesquisa de campo (2011)

Os dados não apontam um consenso sobre quando a auditoria de montadora mais contribui para a melhoria da qualidade. Há um relativo destaque para a fase de desenvolvimento do processo, porém sem concentar a maioria das respostas. Os dados assinalam, no entanto, que nenhum dos pesquisados apontou o momento de crise de qualidade como aquele quando a auditoria mais contribui para a melhoria contínua.

\subsection{Auditorias Internas}

A execução de auditorias internas é exigência da especificação técnica ISO/TS 16949:2009 e, portanto, corrente em todos os fornecedores pesquisados. Entretanto, buscou-se verificar se havia outra motivação além da norma para a execução de auditorias internas na opinião dos pesquisados.

A questão 17 apresenta o seguinte texto: "Na sua opinião, qual das alternativas abaixo melhor completa a frase a seguir: 'Em minha empresa nós realizamos auditorias internas porque ..."'. 
As respostas, apresentadas na Tabela 9, indicam uma ampla maioria (mais de 85\%) dos pesquisados optando pela alternativa: “... elas são ferramentas essenciais na melhoria contínua, além de serem requisitos da ISO/TS e de clientes".

Tabela 9 - Porque as empresas executam auditorias internas

\begin{tabular}{lc}
\hline & PERCENTUAL \\
\hline $\begin{array}{l}\text {... é um requisito da ISO/TS que tem que ser } \\
\text { cumprido, e só. }\end{array}$ & 0,0 \\
\hline$\ldots$ é um requisito da ISO/TS e de clientes. & 5,3 \\
\hline $\begin{array}{l}\text {... elas proporcionam melhoria da qualidade e são } \\
\text { requeridas pela ISO/TS e por clientes. }\end{array}$ & 5,3 \\
\hline $\begin{array}{l}\text {... elas são ferramentas essenciais na melhoria } \\
\text { contínua, além de serem requisitos da ISO/TS e } \\
\text { de clientes. }\end{array}$ & $\mathbf{8 9 , 5}$ \\
\hline \begin{tabular}{l} 
Fonte: Pesquisa de campo (2011) \\
\hline
\end{tabular}
\end{tabular}

Este resultado permite inferir que a auditoria interna é considerada essencial na melhoria contínua, sendo mais que apenas um requisito de norma ou clientes. Esta afirmação consiste em um resultado relevante da pesquisa, pois mesmo com a má reputação da auditoria de um modo geral, destacada por Beckmerhagen et al (2004), onde a mesma é chamada de "mal necessário", a ferramenta em si é considerada como essencial na melhoria contínua.

\subsection{Erros nas Auditorias}

Olhando para o objetivo principal deste trabalho, que é apontar como aumentar a efetividade das auditorias realizadas por montadoras nas autopeças, foi incluída a questão 12, baseada no trabalho de Karapetrovic e Willborn (2000), que lista os principais erros de auditoria, transcrita abaixo:

"Pensando em exemplos de auditorias que pouco (ou nada) agregaram ao processo de melhoria contínua...

Classifiquem, em ordem de importância, os erros listados abaixo. "O número 1 será o que mais tem prejudicado a eficácia das auditorias, o número 2 o segundo que mais tem prejudicado e assim por diante, até o número 9, que representa o que menos tem prejudicado as auditorias realizadas pelos clientes"

As respostas estão na Tabela 10. 
Tabela 10 - Erros que mais tem prejudicado a eficácia das auditorias de montadoras

\begin{tabular}{lcc}
\hline & $\begin{array}{c}\text { PERCENTUAL 1 } \\
\text { (item que mais tem } \\
\text { prejudicado) }\end{array}$ & $\begin{array}{c}\text { PERCENTUAL 2 } \\
\text { (segundo item que } \\
\text { mais tem prejudicado) }\end{array}$ \\
\hline $\begin{array}{l}\text { Uso de auditores não qualificados ou incompetentes } \\
\text { para conduzir uma auditoria }\end{array}$ & $\mathbf{4 2 , 1}$ & $\mathbf{5 , 3}$ \\
\hline Erros nas fases de planejamento das auditorias & 10,5 & 5,3 \\
\hline Quantidade insuficiente de evidências & 10,5 & 0,0 \\
\hline $\begin{array}{l}\text { Avaliação tendenciosa de evidência de auditoria com } \\
\text { relação ao critério de auditoria }\end{array}$ & $\mathbf{2 1 , 1}$ & $\mathbf{3 1 , 6}$ \\
\hline $\begin{array}{l}\text { Uso impróprio ou inadequado de métodos de } \\
\text { amostragem e outras técnicas de auditoria durante a } \\
\text { coleta das evidências }\end{array}$ & 5,3 & 15,8 \\
\hline Falta de reuniões de abertura ou fechamento & 0,0 & 0,0 \\
\hline $\begin{array}{l}\text { Verificação deficiente (ou inexistente) das evidências } \\
\text { coletadas }\end{array}$ & 0,0 & 5,3 \\
\hline $\begin{array}{l}\text { Inconsistências nas evidências e fatos coletados na } \\
\text { auditoria }\end{array}$ & 0,0 & 5,3 \\
\hline $\begin{array}{l}\text { Relatório de auditoria tendencioso, subjetivo ou } \\
\text { indevidamente influenciado }\end{array}$ & 5,3 & 26,3
\end{tabular}

Fonte: Pesquisa de campo (2011)

Dois erros aparecem como os mais citados sejam como "item que mais tem prejudicado" ou "segundo item que mais tem prejudicado". São eles:

\section{a) GRUPO 1}

- Uso de auditores não qualificados ou incompetentes para conduzir uma auditoria.

- Avaliação tendenciosa de evidência de auditoria com relação ao critério de auditoria.

Além dos citados acima, também podem ser destacados os erros:

c) GRUPO 2

- Erros nas fases de planejamento das auditorias.

- Uso impróprio ou inadequado de métodos de amostragem e outras técnicas de auditoria durante a coleta das evidências.

- Relatório de auditoria tendencioso, subjetivo ou indevidamente influenciado.

Foi solicitado aos pesquisados que citassem o que os motivou a marcar o item 1 "que mais tem prejudicado" e também o item 2 "o segundo que mais tem prejudicado". Os principais fatores ligados a cada um dos itens aparecem abaixo.

a) Uso de auditores não qualificados ou incompetentes para conduzir uma auditoria.

O comportamento tendencioso do auditor e sua falta de conhecimento referente ao assunto aparecem como principais motivos para os pesquisados optarem por este item. 
O resultado apontando o "uso de auditores não qualificados ou incompetentes" como o erro que mais tem prejudicado a eficácia das auditorias não chega a ser uma surpresa. Os trabalhos acadêmicos que serviram de base para a pesquisa também abordam a relevância do assunto. Karapetrovic e Willborn (2000) propõem inclusive a aplicação do gráfico de curva da banheira como modelo de desempenho dos auditores ao longo do tempo, com um índice maior de erros na fase da "infância", vide Figura 9.

Segundo os mesmos autores, a fase de qualificação dos auditores deve ser claramente definida e controlada, assim como um sistema de asseguramento da qualidade das auditorias deve estar operante para prover a qualificação necessária antes da obsolescência de critérios e conhecimentos sobre produtos e processos.

Figura 9 - A curva da banheira na auditoria

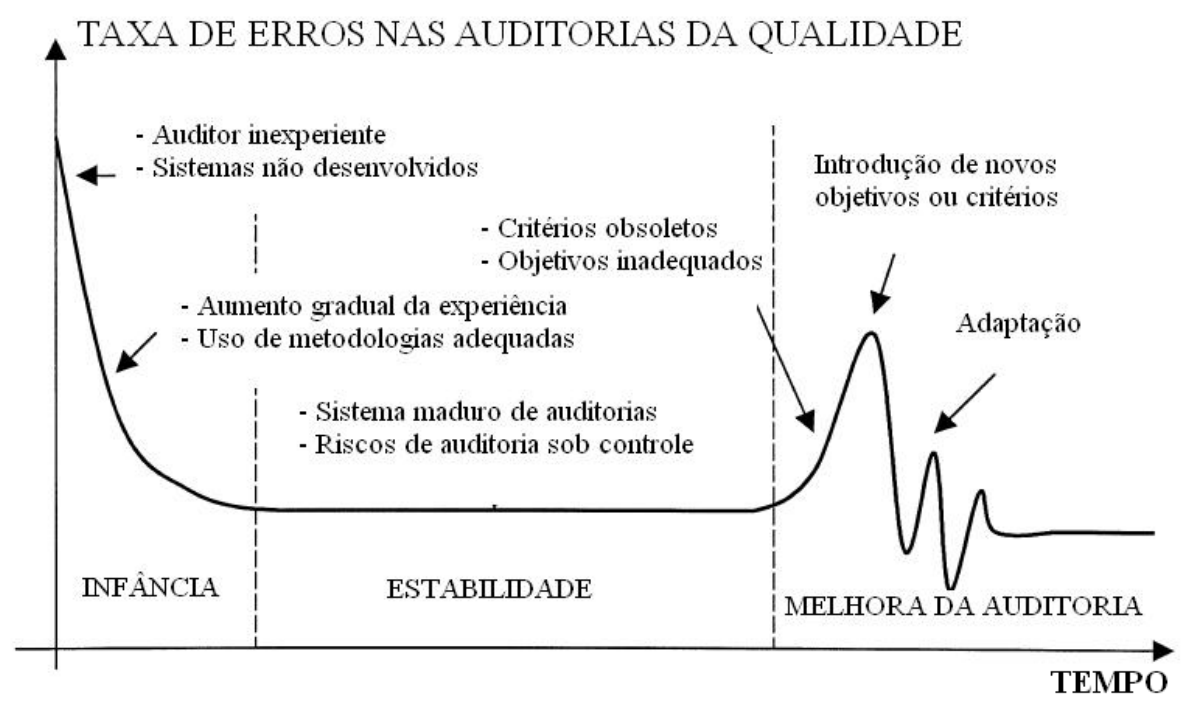

Fonte: Karapetrovic e Willborn (2000, p.694) - Tradução do autor.

b) Avaliação tendenciosa de evidência de auditoria com relação ao critério de auditoria.

Este erro, que foi votado tanto como "segundo item" quanto como "primeiro item que mais tem prejudicado", é apontado principalmente como fruto de um comportamento tendencioso dos próprios auditores. Também é citado o caso onde a auditoria ocorre sob interesses de outras áreas da montadora e seu resultado sofre influências antes mesmo desta começar.

\subsection{Fatores Essenciais Para a Efetividade das Auditorias}

Beckmerhagen et al (2004) listaram cinco fatores que, conjuntamente, são essenciais para a efetividade da auditoria. A questão 14 pergunta como cada um dos fatores é percebido pelos pesquisados, seu texto é apresentado a seguir: 
"Estudos recentes apontam cinco características como essenciais para que uma auditoria seja eficaz". As cinco características estão descritas abaixo. Tomando por base sua experiência com auditorias realizadas por clientes...

Classifique, em ordem crescente de freqüência, as 5 características listadas abaixo. "A número 1 será a menos percebida, a número 2 a segunda menos percebida e assim por diante"

As respostas estão tabuladas na Tabela 11.

Tabela 11 - Como os fatores essenciais à efetividade tem sido percebidos pelos pesquisados

\begin{tabular}{|c|c|c|}
\hline & $\begin{array}{l}\text { PERCENTUAL } 1 \\
\text { (menos percebido) }\end{array}$ & $\begin{array}{l}\text { PERCENTUAL } 2 \\
\text { (segundo menos } \\
\text { percebido) }\end{array}$ \\
\hline $\begin{array}{c}\text { Disponibilidade - auditorias ocorrem quando necessárias, } \\
\text { seja conforme planejamento prévio ou no atendimento de } \\
\text { um problema específico }\end{array}$ & 31,6 & 21,1 \\
\hline $\begin{array}{l}\text { Validade - auditorias são válidas, trazem satisfação e } \\
\text { adicionam valor às partes interessadas }\end{array}$ & 26,3 & 10,5 \\
\hline $\begin{array}{c}\text { Adequação - as auditorias alcançam os objetivos pré- } \\
\text { estabelecidos dentro de um escopo definido, são adequadas } \\
\text { à situação e resposta necessárias no momento de sua } \\
\text { realização }\end{array}$ & 10,5 & 15,8 \\
\hline $\begin{array}{l}\text { Manutenabilidade - as auditorias podem se manter, são } \\
\text { capazes de voltar imediatamente à operação após detecção } \\
\text { de uma falha grave na condução da auditoria ou do processo } \\
\text { auditado, sem perder de vista o plano de trabalho inicial }\end{array}$ & 10,5 & 26,3 \\
\hline $\begin{array}{l}\text { Confiabilidade - auditorias cumprem sua função, produzem } \\
\text { resultados e achados confiáveis e relevantes para a melhoria } \\
\text { contínua }\end{array}$ & 10,5 & 15,8 \\
\hline
\end{tabular}

Fonte: Pesquisa de campo (2011)

É verificado um destaque para os fatores Disponibilidade e Validade, os menos percebidos por uma parcela significativa da amostra. Foram solicitados argumentos para a escolha do item 1 (menos percebido) e item 2 (segundo menos percebido).

O fator Disponibilidade foi apontado como o menos percebido por $31 \%$ e o segundo menos percebido por $21 \%$ dos pesquisados, por diferentes razões:

- Às vezes as auditorias atrapalham o processo produtivo

- Nem sempre ocorrem na data programada

- Ocorrem somente para "cumprir tabela"

- Inflexibilidade dos auditores para reprogramações pedidas pelos fornecedores

O fator Validade foi apontado como o menos percebido por $26 \%$ dos pesquisados. Foram citados a falta de foco na melhoria contínua, o desgaste gerado pela auditoria e o aumento de controles e burocracia após a mesma. 
Foi observado um destaque para o item Manutenabilidade, que foi o citado como o "segundo item menos percebido". Os argumentos para explicar esta escolha foram ligados a exemplos onde a constatação de uma não conformidade grave durante a auditoria acaba por influenciar a continuidade da mesma. Parte dos pesquisados argumenta que os auditores passam a focar muito no problema encontrado e não verificam os outros pontos do processo que podem estar conformidade com os requisitos da norma em questão.

\subsection{Tipos de Auditoria}

- Questão 18:

"Na sua opinião, qual o tipo de auditoria que mais contribui para a melhoria contínua"

Tabela 12 - Tipo de auditoria mais contribui para a melhoria contínua

\begin{tabular}{lc}
\hline & PERCENTUAL \\
\hline $\begin{array}{l}\text { Auditoria interna (feita pela nossa própria empresa, ou a } \\
\text { nosso pedido) }\end{array}$ & $\mathbf{4 7 , 4}$ \\
\hline Auditoria de cliente & 10,5 \\
\hline Auditoria de certificação & 10,5 \\
\hline $\begin{array}{l}\text { Não é o tipo de auditoria que determina isso, mas sim a não } \\
\text { ocorrência dos erros descritos anteriormente }\end{array}$ & $\mathbf{3 1 , 6}$ \\
\hline
\end{tabular}

Fonte: Pesquisa de campo (2011)

A auditoria interna foi a preferida por quase a metade dos pesquisados, seguida pela opção que não citava um tipo de auditoria, mas sim a ausência de erros como principal determinante da eficácia. A auditoria feita por clientes, que é abordada nesta pesquisa, foi citada por apenas $10 \%$ dos pesquisados.

\subsection{Resultados da Auditoria versus Melhoria Contínua}

Auditorias podem ter resultados bons ou resultados ruins. Auditorias com resultados ruins podem ser caracterizadas como auditorias onde um grande número de não conformidades é encontrado. A questão 20 foi incluída para verificar se as auditorias com resultados ruins também contribuiriam para a melhoria contínua. $\mathrm{O}$ texto da questão e as respostas aparecem abaixo:

"Você concorda com a afirmação: 'Uma auditoria de cliente com resultado/nota ruim é a que mais contribui para a melhoria contínua da qualidade?"”

Tabela 13 - Uma auditoria com resultado ruim é a que mais contribui para a melhoria contínua?

\begin{tabular}{lc}
\hline & PERCENTUAL \\
\hline Sim, sempre ou quase sempre (75 a 100\% dos casos) & $\mathbf{5 , 3}$ \\
\hline Sim, na maioria das vezes (50 a 74\% dos casos) & $\mathbf{5 2 , 6}$ \\
\hline Sim, poucas vezes (25 a 49\% dos casos) & 26,3 \\
\hline Não, nunca ou quase nunca (menos de 25\% dos casos) & 15,8 \\
\hline Fonte: Pesquisa de campo (2011)
\end{tabular}


O resultado mostra uma divisão quase simétrica entre "sempre ou quase sempre", "na maioria das vezes" e as alternativas opostas "sim, poucas vezes" e "não, nunca ou quase nunca". Apesar da divisão, é constatado um percentual baixo de opiniões "nunca ou quase nunca". Os dados indicam que, na maioria das vezes, um resultado ruim de auditoria representa uma contribuição para a melhoria contínua da qualidade.

\subsection{Como os Pesquisados Acreditam que a Eficácia possa ser Aumentada}

A última pergunta do questionário era do tipo aberta, com o seguinte texto:

"Descreva o que deve ser feito para aumentar a eficácia da auditoria (realizada pelas montadoras) na melhoria da qualidade das autopeças. Não há limite de espaço. Você pode escrever ou colar um texto de qualquer tamanho na célula amarela abaixo".

As respostas podem ser relacionadas com os erros e fatores apresentados até aqui, e estavam concentradas e dois grupos principais:

O primeiro grupo continha $57 \%$ das respostas (28\% para cada fator).

- Melhorar a qualificação dos auditores;

- Diminuir a avaliação tendenciosa.

Foi citado que deve ser melhorada a qualificação dos auditores tanto em relação às normas de auditoria quanto em relação aos processos de produção auditados. A coerência e um direcionamento para a busca de evidências de conformidade no sistema auditado, em detrimento de uma abordagem tendenciosa foram cobrados pelos pesquisados.

Além dos itens acima, também merece destaque a demanda por evitar "mais papel e burocracia" como subprodutos das auditorias. A pesquisa aponta o "excesso de burocracia" como queixa comum, entretanto, tal item não encontra o mesmo destaque na literatura que embasa este trabalho.

Uma das respostas foi bastante curta e contundente com relação à qualificação de auditores:

"Auditores com conhecimentos da função e dos processos de manufatura. Em minha opinião, não pode ser recém-formado". (E.M., respondente com 32 anos de experiência profissional).

O segundo grupo continha $28 \%$ das respostas ( $14 \%$ para cada fator).

- Dar mais foco no produto e processo;

- Aumentar a freqüência das auditorias e follow-up (acompanhamento) dos planos de ação.

A solicitação para aumento da frequiência das auditorias pode ser relacionada ao fator “disponibilidade”, citado na questão 14 . 
As constantes referências à qualificação de auditores ou posturas tendenciosas encontradas nesta pesquisa podem ser relacionadas ao fato de que o processo de auditoria tem as pessoas como um recurso essencial para seu funcionamento e que fatores psicológicos e organizacionais devem ser levados em conta, conforme descrito por Karapetrovic e Willborn, (2000).

\section{Conclusões}

Tanto a pesquisa de campo quando o referencial teórico aponta que a auditoria é uma ferramenta de melhoria da qualidade difundida e eficaz no meio automotivo. Entretanto, a despeito da reconhecida eficácia no processo de melhoria contínua, a auditoria não possui boa reputação de um modo geral.

A pesquisa de campo foi focada nas auditorias de segunda parte, realizadas pelas montadoras (clientes) nos fabricantes de autopeças (fornecedores). A literatura acadêmica e as normas pesquisadas não são focadas nas auditorias de segunda parte, porém constatou-se com a pesquisa que as etapas do processo de auditoria os erros descritos na bibliografia são observados nas auditorias de segunda parte.

Os fornecedores mantêm programas de auditorias internas da qualidade, que são exigidos pela especificação técnica ISO/TS 16949:2009, entretanto a pesquisa constatou que a efetividade é o fator que mais motiva as empresas a realizarem auditorias internas e não o requisito da ISO/TS 16949.

A efetividade percebida nas auditorias de primeira parte pode ser relacionada com outro item da pesquisa de campo onde as auditorias internas aparecem citadas por $47 \%$ dos pesquisados como as que mais contribuem para melhoria contínua. As auditorias realizadas pelas montadoras são citadas por $10 \%$ dos pesquisados.

As auditorias de segunda parte, que foram o objeto da pesquisa, não são consideradas as mais efetivas na melhoria da qualidade. A ocorrência de erros e a falta de fatores essenciais para a auditoria são as causas desta queda na efetividade da mesma.

Os resultados da pesquisa de campo estão alinhados com os da bibliografia, com destaque para os estudos de Karapetrovic e Willborn (2000; 2002). Erros relacionados à competência e à conduta dos auditores são os fatores que mais tem prejudicado a efetividade das auditorias. A falta de conhecimento sobre processos de fabricação, falhas de amostragem e atitudes tendenciosas são apontados como os erros que mais tem influenciado negativamente as auditorias das montadoras. Erros são percebidos, mas fatores essenciais como realizar as auditorias conforme planejamento, ou para atender uma situação de urgência e realizar auditorias que agreguem valor não tem sido observados pelos pesquisados. 
A competência e a conduta dos auditores são essenciais para a efetividade da auditoria e são tratadas tanto em normas internacionais como a ISO 19011:2011 quanto na literatura acadêmica pesquisada. Autores como Munro (2003), Russell (2007), Berckmerhagen et al (2004) e Karapetrovic e Willborn (2000; 2002) dão especial destaque aos temas competência e conduta dos auditores. É relevante citar que a norma ISO 19011:2011 foi publicada alguns meses após a pesquisa de campo e contém um aumento do texto referente à competência e conduta dos auditores, quando comparada à sua versão anterior.

Ações para medir e aumentar a competência dos auditores aparecem como necessárias para o aumento da efetividade das auditorias, visando dimuição dos erros de auditoria mais percebidos na pesquisa.

Permitir um planejamento conjunto (montadora e fornecedor) para a realização das auditorias pode ser uma alternativa para permitir que a auditoria seja feita "quando necessária", que é um fator essencial para a efetividade da mesma. Auditorias fora do planejamento ou para "cumprir tabela" foram apontadas na pesquisa.

Novos trabalhos podem ser feitos para aprofundar os estudos e possibilitar definição de ações de melhoria mais específicas.

\begin{abstract}
Audit process has never had a good reputation. Both financial and non-financial audits (including quality audits) have their effectiveness frequently questioned. This research's goal is to identify how to increase the effectiveness of audits performed by automakers on its suppliers. The method used is the questionnaire, filled out by experienced professionals of Brazilian parts suppliers, who are constantly being audited by automakers. It has been verified that despite its reputation, quality audit is considered effective in a majority of cases and also that issues of auditor's competence and qualification, plus biased evaluations of audit evidences are the main causes of audit's effectiveness reduction. Some improvement action proposals are presented.
\end{abstract}

Keywords: Quality, Audit, Automakers.

\title{
Referências
}

ANDERSON, D. R.; SWEENEY, D. J.; WILLIAMS, T. A. Estatística aplicada à administração e economia. 2. ed São Paulo: Cengage Learning, 2008.

ANFAVEA. Associação Nacional dos Fabricantes de Veículos Automotores. Anuário da Indústria Automobilística Brasileira, 2012.

ARTER, D. R. Quality audits for improved performance, 3 ed. Milwaukee: ASQ Quality press, 2003.

AUTOMOTIVE INDUSTRY ACTION GROUP (AIAG). ISO/TS 16949:2002 Implementation Guide. 1. ed Michigan: 2003.

BECKMERHAGEN, I. A. et al. Case study on the effectiveness of quality management system audits. The TQM Magazine, vol. 16, n. 1, p. 14-25, 2004. 
EFETIVO In: CEGALLA, D. P. Dicionário escolar da língua portuguesa / Domingos Pascoal Cegalla, 2. ed. São Paulo: Companhia Editora Nacional, 2008, p.328.

EFFECTIVE In: Webster's New Dictionary of the English Language. 1 ed. New York: 2002, p.106.

GARDNER, R. A. The process-focused organization: a transition strategy for success. 1. ed. Milwaukee: ASQ Quality Press, 2004.

HAMMER, M. The Agenda. 2 ed. California: Three Rivers Press, 2003.

HERNANDEZ, H. Quality audit as a driver for compliance to ISO 9001:2008. The Total Quality Management Journal, v. 22, n. 4, p.454-466, 2010.

INTERNATIONAL STANDARDIZATION ORGANIZATION (ISO). Quality management systems - Particular requirements for the application of ISO 9001:2000 for automotive production and relevant service part organizations. ISO/TS 16949. 3 ed. Genebra: ISO, 2009.

INTERNATIONAL STANDARDIZATION ORGANIZATION (ISO). Guidelines for auditing management systems. ISO 19011. 2 ed. Genebra: ISO, 2011.

IWAARDEN, J. V.; WIELE, T. V.; WILLIAMS, R. A management control perspective of quality management. International Journal of Quality and Reliability Management, vol. 23, n. 1, p. 102-112, 2006.

KARAPETROVIC, S.; WILLBORN, W.; Self-audit of process performance. International Journal of Quality and Reliability Management, vol. 19, n. 1, p. 24-45, 2002.

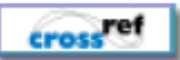

294,2000

Generic audit of management systems: fundamentals. Managerial Auditing Journal, vol. 15, n. 6, p. 279-

cross ref

Quality assurance and effectiveness of audit system. International Journal of Quality and Reliability Management, vol. 17, n. 6, p. 679-703, 2000.

cross ref

LIEBESMAN, S.; The Right Approach. Quality Progress, p. 60-63, Setembro, 2009.

MALHOTRA, M. K; GROVER, V. An assessment of survey research in POM: from constructs to theory. Journal of Operations Management, vol. 16, p. 407-425, 1998.

cross ref

MARCONI, M. A; LAKATOS, E. M. Técnicas de Pesquisa 7. ed. São Paulo: Atlas, 2008.

MUNRO, R. A.; Automotive Internal Auditor Pocket Guide: Process Auditing to ISO/TS 16949:2002. $1 \mathrm{ed}$ Milwaukee: ASQ Quality press, 2004.

POWER, D.; TERZIOVSKI, M. Quality audit roles and skills: Perceptions of non-financial auditors and their clients. Journal of Operations Management, vol. 25, p. 126-147, 2006.

PSA PEUGEOT CITROËN. Audit Synthèse qualité vie série. Norme Qualité Q620450, 1999.

RUSSELL, J. P. The Internal Auditing Pocket Guide: Preparing, Performing, Reporting and follow-up. 2. ed. Milwaukee: ASQ Quality Press: 2007.

SANTOS, S. B. Certificação ISO 9001/2000: Uma avaliação sobre o processo de implementação no IV Juizado Especial Cível do Tribunal de Justiça do Estado do Rio de Janeiro. Dissertação de Mestrado: UFRRJ, 2007. 
SILVA, E. Uma análise das práticas de asseguramento da qualidade de produtos e processos antes do início da produção em série adotadas por empresas do ramo automotivo. Dissertação de Mestrado: UFF, 2009.

VERGARA, S. C. Métodos de Pesquisa em Administração 3. ed. São Paulo: Atlas, 2008.

Projetos e Relatórios de Pesquisa em Administração 10. ed. São Paulo: Atlas, 2009.

WONG, A. Sustaining company performance through partnering with suppliers. International Journal of Quality and Reliability Management, vol. 19, n. 5, p. 567-580, 2002.

cross ref

WRIGHT, J. T. C.; GIOVINAZZO, R. A. Delphi - Uma ferramenta de apoio ao planejamento prospectivo. Caderno de pesquisas em administração, v. 1, n. 12, p. 54 - 65, USP, 2000.

ZHANG, C.; HENKE JUNIOR, J. W.; GRIFFITH, D. A. Do buyer cooperative actions matter under relational stress? Evidence form Japanese and U.S. assemblers in the U.S. automotive industry. Journal of Operations Management, n. 27, p. 479-494, 2009.

\section{Dados dos autores:}

Nome completo: Alexandre Casimiro da Silva

Filiação institucional: MAN Latin America

Departamento: Estratégia do Produto e Gerenciamento de Portfolio

Função ou cargo ocupado: Consultor

Endereço completo para correspondência: Rua Darci de Carvalho, 710. Bairro: Morada da Colina,

Resende, RJ - 27523-100

Telefones para contato: (24) 21091038

E-mail: alexandrebama@hotmail.com

Nome completo: Stella Regina Reis da Costa

Filiação institucional: Universidade Federal Rural do Rio de Janeiro - UFRRJ

Departamento: Departamento de Tecnologia de Alimentos

Função ou cargo ocupado: Professora Titular

Endereço completo para correspondência: Travessa dos Tamoios 40, apt 601-Flamengo, Rio de

Janeiro-RJ, Brasil CEP:22230-050

Telefones para contato: (21) 25563207

E-mail: stella@ufrrj.br

Enviado em: 08/11/2011

Aprovado em: 19/01/2013 